\title{
La invisibilidad de la identificación de víctimas en las fuerzas militares y el inicio de una crisis en la defensa y seguridad nacional a raíz del Acuerdo de Paz*
}

\section{The Invisibility of the Identification of Victims in the Military Forces and the Beginning of a Crisis in National Defense and Security Following the Peace Agreement}

Paola Alexandra Sierra-Zamora ${ }^{\mathrm{a}}$

Escuela Superior de Guerra, Colombia

paola.sierra@esdegue.edu.co

ORCID: https://orcid.org/0000-0002-3146-7418

Manuel Bermúdez Tapia

Universidad Privada San Juan Bautista, Perú

ORCID: https://orcid.org/0000-0003-1576-9464
DOI: https://doi.org/10.11144/Javeriana.vj69.iivf

Recibido: 17 Octubre 2019

Aceptado: 07 Febrero 2020

Publicado: 30 Diciembre 2020

\section{Resumen:}

Una de las referencias más importantes que ha generado el conflicto armado interno en Colombia es la acreditación de la participación (activa y subalterna) de las fuerzas militares. De este modo, El Ejército ha tenido un enfrentamiento directo con diferentes grupos guerrilleros, y han participado en el proceso de atención de la seguridad en el ámbito nacional, al cumplir las disposiciones de las autoridades del Gobierno Nacional conforme a sus objetivos institucionales y compromiso democrático. Sin embargo, dichas acciones pueden generar una situación negativa, especialmente en un aspecto poco evaluado: la proyección personal y profesional en los futuros miembros de las fuerzas militares, que podrían quedar desacreditados tanto por su propio Estado como por la sociedad nacional, sin que se haya hecho una correcta evaluación de sus acciones. En el ámbito comparado, esta situación se registra en el Perú, donde las fuerzas armadas tuvieron un déficit de personal tras la finalización de la lucha antiterrorista, lo que nos permite proyectar una posible situación negativa en Colombia. Entonces, surgen dos elementos muy importantes a tratar: la situación jurídica de las víctimas del conflicto armado interno - desde personas naturales hasta los integrantes de las fuerzas militares; y el hecho de que el Acuerdo de Paz otorga mejores y mayores derechos a quienes actuaron en contra de la defensa y seguridad nacional del país, y contra los integrantes de las fuerzas militares. En consecuencia, surge un proceso de invisibilización de víctimas hacia los integrantes de las fuerzas militares.

Palabras clave: Conflicto armado, seguridad nacional, defensa nacional, víctimas, fuerzas militares, Colombia, invisibilización de víctimas.

\begin{abstract}
:
One of the most important references generated by the internal armed conflict in Colombia is the accreditation of the military forces' active and subaltern participation. In this way, the military Forces have had a direct confrontation with different paramilitary groups and have participated in the process of security attention at the national level by complying with the provisions of the National Government authorities, according to their objectives Institutional and democratic commitment. However, such actions can generate a negative situation, especially in a poorly evaluated aspect: the personal and professional projection in future military members who may be discredited, both by the State and society without executing a correct evaluation of their actions. In the comparative field, this situation is recorded in Peru, where the Armed Forces had a personnel deficit at the end of the fight against terrorism which allow us to project a possible negative situation in Colombia. Two essential elements emerge: the legal situation of the victims of the internal armed conflict - from individuals to members of the military forces-; and the fact that the Peace Agreement grants better and greater rights to those who acted against the country's defense and national security, and against the members of the military forces. Consequently, there is an invisibilization of victims that were members of the military forces.
\end{abstract}

Keywords: armed conflict, national security, national defense, victims, military forces, Colombia, invisibility of victims.

Notas de autor

a Autora de correspondencia. Correo electrónico: paola.sierra@esdegue.edu.co 


\section{Introducción}

Durante más de cincuenta años, en Colombia se ha registrado un conflicto armado interno, donde el Estado ha tenido que actuar frente a diferentes grupos insurgentes, tanto paramilitares como guerrillas. Por esta razón, el Gobierno Nacional ha actuado de modo diferente ante cada problema, ya que los elementos de análisis para cada situación eran particulares. Prueba de ello es que uno de los primeros grupos de guerrillas - las Fuerzas Armadas Revolucionarias de Colombia, Ejercito del Pueblo (FARC-EP)—, ha optado por incorporarse a la vida política del país, por lo que se estudiaron diferentes alternativas para llegar a ello.

Tomando en cuenta esta referencia histórica, el proceso para llegar a un entendimiento en beneficio del país permitió que el Gobierno Nacional colombiano y las FARC-EP llegara a un Acuerdo de Paz. Esta resolución ha provocado una serie de referencias constitucionales, jurídicas y políticas que no han tomado en cuenta a las fuerzas militares, a pesar de que estas han sido parte activa en el conflicto armado interno.

Un tema que se ubica en un ámbito secundario es el hecho de que las fuerzas militares han actuado bajo un sometimiento al orden democrático y han mostrado la voluntad de ser parte del proceso de pacificación del país. Sin embargo, se ha generado una situación de incertidumbre tanto en el personal, como en las familias de los militares.

Esta situación parte del hecho de que las tratativas y el mismo Acuerdo de Paz entre el Gobierno y las FARC-EP generan algunos puntos controversiales con respecto al ánimo y voluntad de servicio en los integrantes de las fuerzas militares:

- Los integrantes de las FARC-EP tendrán un sistema de juzgamiento especial, y probablemente en algunos casos no se llegue a establecer una verdadera acción punitiva por los delitos cometidos, si es que se identifican.

- Los exguerrilleros accederán a una condición civil que les facilita participar en la vida política del país, con una capacidad para modificar la legislación nacional y, por ende, intervenir en la dirección y toma de mando de la Defensa y Seguridad Nacional del país.

- Hay registro de una serie de acciones alternas al conflicto armado interno por parte de algunos integrantes de las FARC-EP, especialmente la vinculación con el narcotráfico y otros hechos delictivos. Ante ello, surge la posibilidad de que estos hechos puedan quedar impunes.

Sobre estas referencias, los anteriores enemigos del país podrían alcanzar mejores condiciones de vida que los militares a quienes enfrentaron. Eventualmente, esto se podría registrar en la Justicia Transicional, y de la misma Jurisdicción Ordinaria — donde es posible evaluar la continuidad de los procesos contra los integrantes de las fuerzas militares por actos desarrollados en el conflicto armado interno-. Esto provocará un ánimo adverso en las tropas y en las personas que tengan un proyecto de vida al servicio del país como parte de las instituciones militares.

El proceso de invisibilización a uno de los actores más importantes del conflicto armado resulta acreditado por estos hechos. Este patrón nos permite hacer un análisis comparativo en Perú, donde las fuerzas armadas registraron un déficit de personal entre los años 2000 y 2010, especialmente porque los ciudadanos —en particular los jóvenes peruanos ubicados en zonas donde había enfrentamiento con los grupos terroristas -, veían a las fuerzas militares como perpetradoras de violaciones de Derechos Humanos, en particular por los hechos sucedidos en Ayacucho, Apurímac y Pichari, donde habían enfrentamientos contra Sendero Luminoso; así lo detallan Carlos Basombrio y Fernando Rospigliosi ${ }^{1}$.

Luego de que la Corte Interamericana de Derechos Humanos emitiera las sentencias en los Casos La Cantuta y Barrios Altos ${ }^{2}$, se desencadenó un hito histórico en las fuerzas armadas peruanas, pues se registró un mínimo de personal operativo, un presupuesto exiguo, y un nivel de operatividad debajo de lo mínimo 
conforme detalla el propio Ejército Peruano en su Manual directriz, informe de gestión y autoevaluación institucional.

Por tanto, si en el vecino país se observó una crisis institucional a raíz del cuestionamiento, tanto social como institucional, al personal militar, además de ser procesados por las acciones militares ejecutadas en el conflicto armado interno, ¿por qué esto no sucedería en Colombia?

Ante esta situación, el análisis de la realidad colombiana permite proyectar que las fuerzas militares serán afectadas en forma objetiva, tanto a nivel institucional como de su propia sostenibilidad operativa. Muchos jóvenes militares podrán tomar como referencia negativa el no ser catalogado como víctima si surge una situación de conflicto armado; hecho que se amplificaría si una parte de las FARC-EP anuncia la continuidad de sus actos de insurgencia.

En consecuencia, en el actual proceso de institucionalización de la Justicia Transicional en Colombia, es posible identificar referencias negativas y ambiguas que pueden generar una condición limitativa a la paz que se procura alcanzar, y que provocan una diferenciación entre las victimas del conflicto armado interno. Para lograr una diferenciación eficaz, se requiere detallar un contexto muy particular con base en un proceso metodológico que permita identificar la dimensión del presente texto.

En primer término, se entiende por víctima a "aquellas personas que, individual o colectivamente, hayan

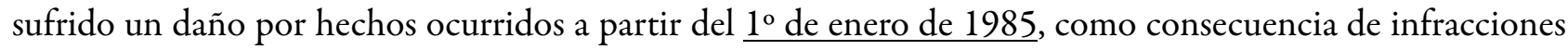
al Derecho Internacional Humanitario o de violaciones graves y manifiestas a las normas internacionales de Derechos Humanos ${ }^{4}$, ocurridas con ocasión del conflicto armado interno" ${ }^{5}$, conforme al artículo 3 de la Ley 1448 del 10 de junio de 2011. En esta ley se dictan medidas de atención, asistencia y reparación integral a las víctimas del conflicto armado interno, entre otras.

Este contenido normativo nos permite detallar:

- Una referencia que incluye a un conjunto muy amplio de individuos, situación que no excluye a los integrantes de las fuerzas militares de Colombia. Una normatividad exequible, conforme a la Sentencia C-250 de 2012 por la Corte Constitucional colombiana, respecto a la parte subrayada del artículo 3 de la Ley 1448 de 2011, que detalla la temporalidad de las acciones de enfrentamiento con armas en las cuales han participado las fuerzas militares de Colombia ${ }^{6}$.

- Una normatividad exequible, conforme a la Sentencia C-280 de 2013, respecto a la parte en cursiva del artículo 3 de la Ley 1448 de 2011 que puntualiza, en forma expresa, el modo en el cual es posible identificar víctimas, en particular en las fuerzas militares de Colombia ${ }^{7}$.

- Una normatividad exequible, conforme a la Sentencia C-161 de 2016, respecto al párrafo $1^{\circ}$ del artículo 3 de la Ley 1448 de $2011^{8}$.

- Una normatividad que fue ampliada por la Corte Constitucional colombiana en la Sentencia T-092 de 2019 se hizo en el caso de situaciones convivenciales (compañero permanente) que hubieran sido victimadas por las FARC-EP. Así sucedió en el caso de la señora Luz Marina Camacho Ramos, respecto a su trámite ante la Unidad Administrativa Especial para la Atención y Reparación Integral a las Víctimas (UARIV). Un factor de referencia importante, pues en este punto ya se incluye a la familia de los integrantes de las fuerzas militares de Colombia, quienes son actores importantes en las decisiones de continuar o retirarse de la institución; en particular cuando surge una situación negativa en la integridad del familiar que es militar?.

En segundo término, se debe evaluar la situación de los miembros de las fuerzas militares que pudieren ser considerados víctimas. Por tanto, corresponde detallar algunas referencias que podrían limitar los derechos fundamentales de estas personas, en cuanto a una accesibilidad a la condición de víctima del conflicto armado interno, que también podría afectar la propia institucionalidad de la Defensa y Seguridad Nacional. 
La referencia normativa aplicable al contexto de víctima permite evaluar el marco de la legalidad aplicable al caso del personal de las fuerzas militares de Colombia, ya que este es un factor que, además de ser constitucional y legítima ${ }^{10}$, no admite una diferenciación negativa frente a las víctimas que formaron parte de las FARC-EP.

\section{La afectación de derechos de los integrantes de las fuerzas militares con respecto al conflicto armado interno, y su invisibilidad ante su categorización como víctima}

Tomando en cuenta el hecho de que el concepto de víctima, según Ley 1448 de 2011, es un valor general y abstracto, podemos observar dos situaciones que van a provocar una diferenciación de referencias. Estas circunstancias permiten detallar que los miembros de las fuerzas armadas de Colombia tendrán un valor limitado frente a una víctima que ha formado parte de las FARC-EP:

- El acceso a cargos públicos en el Estado a través de procesos democráticos. La diferenciación en dos subniveles de víctimas permitirá detallar que, a raíz de un mismo hecho, surgirán dos referencias:

Un integrante de las fuerzas militares que ha participado de un proceso penal — respecto a hechos vinculados a la comisión de un delito-, continuará en el trámite de dicho proceso mientras se determine su culpabilidad o su inocencia. En cambio, a raíz del Acuerdo de Paz, algunos integrantes de las FARC-EP, cuya participación en actos criminales ha sido totalmente identificada, podrían verse librados de una eventual condena. El alcance punitivo ha sido sometido a una evaluación que involucra una acción del Estado en aras a alcanzar un proceso de paz, pero que, en definitiva, perjudica a un sector que ha estado en confrontación directa con los ahora beneficiados del Acuerdo de Paz. Una referencia negativa que permite detallar una de las razones por las cuales la población colombiana no acepta las condiciones del Plebiscito de 2016.

- La evaluación de la condición de víctima, respecto al daño: referencia sustancial que permite detallar que los miembros de las fuerzas militares, por su condición administrativa y laboral, deben informar de tal situación a sus comandos superiores, elemento que no se observa en el contexto de la contraparte. El nivel de auto percepción para ser considerado o no como víctima, admite dos referencias que resultan contradictorias entre sí, y que contradicen el espíritu de la norma que determina el alcance del término víctima.

\section{La afectación a la Defensa y Seguridad Nacional cuando los integrantes de las fuerzas militares que hayan participado en el conflicto armado no resulten calificables como víctimas}

En este punto se evalúan el interés, la legitimidad y vinculación del miembro del Ejército colombiano, como integrante de la fuerza pública, para ser parte del proceso de la Justicia Transicional, principalmente porque su condición se evalúa en un nivel difuso que anula su individualidad. Nótese que el integrante de las fuerzas militares tiene un rol por parte del Estado y de la Fuerza Pública, por lo que su condición de parte esencial en el conflicto armado queda anulada en el posacuerdo.

Sobre la base de lo detallado, debemos considerar que el factor humano de las fuerzas armadas —en el ámbito comparado-, es tomado en cuenta por el Estado, el Gobierno Nacional, el Comando de las fuerzas armadas y la Administración Pública ${ }^{11}$, por cuanto permite la identificación, sincretismo y asimilación del individuo con su comando e institución. Si no se brindan las garantías del caso, las referencia antes detalladas 
pueden anular el espiritu de pertenencia a las fuerzas militares por parte de sus integrantes, elemento que se relaciona directamente con la defensa y seguridad nacional, porque genera un paso al retiro de forma voluntaria.

Esta referencia ha sido registrada por las fuerzas armadas del Perú, especialmente entre los años 1983 y 1987, donde hubo una mayor intervención militar contra Sendero Luminoso. Esto provocó la intervención del personal militar sin preparación en zonas de conflicto, quienes generaron una mayor reacción de las huestes senderistas, conforme detalla Ricardo Melgar ${ }^{12}$.

En consecuencia, el impacto negativo que sufrirán las fuerzas militares colombianas permitirá observar una reducción de su nivel de operatividad e institucionalidad, ya que no habrá personal que cubra los requerimientos logísticos de las instituciones armadas.

\section{La conceptualización de elementos referenciales sobre defensa y seguridad nacional}

Tomando en cuenta el alcance de la Justicia Transicional, se debe evaluar la Ley 684 de 2001, que fue declarada inconstitucional por la Sentencia C-251 de 2002 por la Corte Constitucional ${ }^{13}$.

Esta ley tenía una connotación negativa en cuanto a la obligación del Estado de velar por los derechos humanos - respecto a la normatividad que regula un Estado de Excepción-, porque generaba una limitación a la autonomía de los ciudadanos. A estos se le sometía a una subordinación total ante el poder ejecutivo y la fuerza pública, condición que generó una contradicción sustancial sobre lo que determina el Derecho Internacional Humanitario (DIH).

Al generarse una contradicción normativa — donde debían ponderarse entre obligaciones internacionales y acciones en el ámbito interno respecto a la generación de políticas públicas sobre defensa y seguridad nacional —, la articulación de toda acción del Estado debía estar bajo el marco constitucional ${ }^{14}$.

La legitimidad de la política de Estado sobre defensa y seguridad nacional, determinada por la propia Constitución, es desarrollada a través de políticas públicas que permitan guiar las directrices de las políticas de gobierno. Estas deben suceder en la gestión del poder del Gobierno nacional para dar cumplimiento a las disposiciones constitucionales — sin importar las condiciones a las que se enfrenta -, para garantizar la seguridad, la defensa y la paz en el territorio patrio ${ }^{15}$.

Nótese que por el alcance amplio de las políticas de defensa y seguridad nacional, se requiere puntualizar teóricamente en estas, así como en el conflicto armado interno, la prevención ante situaciones de riesgo o emergencia social, la amenaza a la legalidad y paz social, entre otros, para lo cual detallaremos las referencias a continuación.

\section{Defensa nacional}

Se refiere a las actividades y políticas que desarrollan los Estados modernos para evitar o rechazar los ataques militares que se pudieran realizar en su contra, los cuales afectasen su soberanía, como también los que generasen un impacto negativo en cuanto a la administración de su territorio, población y recursos naturales. En general, son las actividades que ejecutan las fuerzas armadas en el ámbito de la guerra, como actividad militar entre Estados, respecto a las relaciones internacionales que se establezcan entre estos.

Esta referencia ha requerido de una adaptación a los tiempos actuales, puesto que la guerra contemporánea ya no se limita a la anexión o administración de un territorio, tal como sucedía entre los siglos XVI y XX, porque en el ámbito internacional todavía subsiste el impacto negativo de la II Guerra Mundial.

Por ello, en la actualidad, la guerra implica una variación de objetivos $^{16}$, que consisten en: 
- La apropiación de recursos, donde destaca la política de acceso a reservas de gas, petróleo, y recursos minerales de necesidad en el proceso industrial de un país. Las caídas de los gobiernos de Sadam Hussein en Irak $^{17}$, y Muamar el Gadaffi en Libia ${ }^{18}$, pueden plantear la referencia de que los Estados que intervinieron en dichos países no buscaban la democracia ni la satisfacción del pueblo, porque de por medio estaba el acceso a una red de suministros esenciales para sus economías.

- La apropiación de tecnología de punta, en particular la vinculada a la fabricación de armamento y equipos para el desarrollo de la industria aeroespacial. Referencia que permitió la exculpación de responsabilidades a científicos alemanes por crímenes cometidos en la II Guerra Mundial. Tras nacionalizarse como norteamericanos, se permitió que este Estado desarrollara la bomba atómica y la carrera espacial ${ }^{19}$.

- La provisión de materias primas estratégicas.

- El abastecimiento de agua y alimentos, que se evidencia con particularidad entre Israel y Palestina ${ }^{20}$.

Si tomamos en cuenta las consecuencias del Acuerdo de Paz en la futura merma de personal en las fuerzas militares, el impacto negativo que asumirá el Estado colombiano con respecto a su propia integridad debe ser revaluado. Incluso el nivel de gravedad se incrementa si se toma en cuenta el avance o proyección del narcotráfico en países como Perú, Bolivia, México y Colombia.

La consecuencia, finalmente, será trasladada a la ciudadanía, que verá debilitado el concepto de bien común con respecto a la defensa y seguridad nacional. Con ello, la invisibilidad en la generación de las víctimas en las fuerzas militares genera una proyección negativa que alcanzaría a toda la población del país.

\section{Seguridad nacional}

La seguridad nacional es un concepto complicado de definir, en tanto cada Estado lo determina en función de las realidades que observa en su desarrollo político, económico, social y militar ${ }^{21}$.

Esta referencia es particular para el caso de Colombia, no tiene equivalente en el ámbito comparado, y nos permite detallar la importancia de identificar a los actores que resultaron afectados por el conflicto armado establecido en varios frentes y niveles, en los cuales las víctimas no son de fácil identificación cuando estos forman parte de la fuerza pública o en particular de las fuerzas militares.

$\mathrm{Su}$ particularidad se amplía en una evaluación comparativa, porque el contexto internacional ha transformado nuevas realidades y, por ende, se ha incidido en la regulación normativa de los paises sobre Seguridad Nacional, al partir del mismo hecho de la diferenciación de país con respecto a un Estado.

Esto explica las razones por las cuales el manejo de la seguridad nacional está vinculado a un contexto internacional para unos países, y para otros está sometido a las crisis que se generan por la contradicción de la relación nación-Estado, en función de conflictos internos, porque para Colombia está vinculado a la crisis que se genera por la contradicción que se generó en el Estado-Nación durante el siglo $\mathrm{XX}^{22}$.

\section{Conflicto armado}

Según el Derecho Internacional Humanitario, un conflicto armado sería todo enfrentamiento violento entre dos grupos humanos de tamaño masivo y que, generalmente, tendrá como resultado muertes y destrucción material ${ }^{23}$. Este concepto es superior al de guerra civil por la intervención de elementos fluctuantes o flexibles que pueden implicar condiciones de anonimato entre las partes. Sus acciones provocan muertos, heridos o desaparecidos, en un contexto dúctil y permeable en el tiempo, en función de las condiciones que se van generando $^{24}$. 


\section{Conflicto armado interno}

En los últimos años, Colombia se ha encontrado en un contexto de extrema violencia social. Esto ha generado un problema estructural e histórico que registra un impacto derivado de los ámbitos interno y externo, principalmente debido al contexto provocado por las acciones derivadas de grupos guerrilleros.

Como consecuencia, no se ha hecho de forma eficaz un registro estadístico detallado del número de total de crímenes y víctimas. Téngase en cuenta el elevado nivel de recursos institucionales y humanos que implicaría, y que ante el espectro de problemas de estadística y archivo que ese tipo de estudios siempre ha tenido, se haría imposible alcanzar este objetivo ${ }^{25}$.

De igual manera, Colombia es un país que rompe cualquier estadística; tanto es así que una de las víctimas de la denominada época de la violencia (durante los años cuarenta y cincuenta en el país), fue Manuel Marulanda Vélez, alias Tiro Fijo, quien se desplazó forzosamente de su hogar a causa de su pertenencia al Partido Liberal ${ }^{26}$.

\section{Situación de riesgo}

Es la probabilidad de que suceda un evento, impacto o consecuencia adverso - entendido también como la medida de la posibilidad y magnitud de los impactos adversos. Los miembros de las fuerzas militares de Colombia han tenido el conocimiento de que podían tener algún enfrentamiento contra los grupos insurgentes en el país. A pesar de esta situación, optaron por disminuir su propia seguridad, en aras de garantizar una defensa y seguridad nacional. Este hecho no puede quedar limitado o condicionado a situaciones legales que provocan una modificación de la constitución. En esta se puede detallar que los integrantes de grupos insurgentes adquieren mejores condiciones políticas y sociales, frente a los que tienen los miembros de las fuerzas militares, tras la finalización de los combates entre ambas agrupaciones.

\section{Situación de prevención a cargo del Estado ante riesgos sociales}

La ONU menciona que debe haber una "adopción de medidas encaminadas a impedir que se produzcan deficiencias físicas, mentales y sensoriales (prevención primaria), o a impedir que las deficiencias tengan consecuencias físicas, sicológicas o negativas" ${ }^{27}$. Con respecto a ello, se debe detallar que, tras la firma del Acuerdo de Paz entre el Gobierno Nacional y las FARC-EP, se debe proyectar en el país un período de paz sostenible en el tiempo.

Por tanto, resulta necesario evitar la generación de nuevas víctimas, y conforme lo detallado en los puntos precedentes, los integrantes de las fuerzas militares colombianas están en una situación de desventaja cuando se les califica como víctimas del conflicto armado.

\section{Situación de vulnerabilidad}

Es la exposición a contingencias, y la tensión y dificultad para afrontarlas. "La vulnerabilidad registra dos partes: una externa a los riesgos y convulsiones a los cuales está sujeto un individuo o a una sociedad; y una interna que es la indefensión, esto es, una falta de medios de afrontar la situación sin perdidas perjudiciales" 28 .

En el ámbito de la institucionalidad de las fuerzas militares, y del personal de estas instituciones, resulta acreditable la vulnerabilidad de su situación cuando se pasa de ser parte activa del conflicto armado a serlo de una etapa de pacificación. Durante este ciclo se deberá asumir una condición secundaria y supeditada a 
una evaluación preliminar administrativa, donde el personal que ha resultado víctima en la lucha contra las FARC-EP no podrá ver materializada una reparación.

El impacto negativo sobre las familias de los militares colombianos resultará ser un factor que condicionará la participación de jóvenes que quieran formar parte de la defensa y seguridad nacional.

\section{La articulación de los conceptos previos en la identificación de una invisibilización de víctimas en los integrantes de las fuerzas militares}

Con las referencias conceptuales previas, se debe enfatizar en la necesidad de generar una verdadera paz social en Colombia, donde las víctimas no deban ser identificadas o catalogadas por su condición personal, profesional, o por su situación en el conflicto armado interno. De ser así, se estaría generando una situación negativa que, a la larga, afectará la institucionalidad de las fuerzas militares y a la propia defensa y seguridad nacional, conforme se ha podido evidenciar en el caso de Perú.

Por ello, es necesario otorgar a las víctimas del conflicto armado interno un papel fundamental dentro de los procesos encaminados, para que así el Acuerdo de Paz tenga una legitimidad social ${ }^{29}$, y supere el actual contexto, en el cual es posible detallar referencias que no generan una homogeneidad en la identificación de las víctimas ${ }^{30}$.

Esta referencia es crucial, puesto que la anterior afirmación es confirmada por la Unidad para Atención y Reparación Integral a las Víctimas (UARIV), que data un número de siete millones de víctimas del conflicto armado. La referencia numérica permite proyectar un radio de alcance nacional que impone la obligación del Estado, y de toda la comunidad nacional, de tener en cuenta este hecho tan dramático si se quiere asumir un verdadero estado de bienestar social al posacuerdo.

En este punto, las víctimas que forman parte de la fuerza Ppública, sea como funcionarios públicos o miembros de las fuerzas militares que no han sufrido un daño físico, ven limitadas sus opciones para plantear un daño psicológico que pudiera incluirlos en este contexto referencial. Este punto no puede quedar supeditado a una referencia secundaria o accesoria frente a las acciones que desarrollan la Justicia Transicional.

Nótese que el conflicto interno colombiano ha sido una lucha por intereses económicos y políticos sin coherencia ideológica $^{31}$, al dejar de lado los intereses del pueblo. Este enfrentamiento se considera el más antiguo del continente americano, y uno de los más sangrientos ${ }^{32}$. Por esta razón no se puede incluir en una posición secundaria a quien fue artífice de la estabilidad social y del acceso a la paz en el país: las fuerzas militares.

\section{La evaluación de las etapas del posconflicto y del posacuerdo, respecto a los miembros de las fuerzas militares de Colombia}

El posconflicto en Colombia debe ser analizado como una situación de 'salida o superación de la guerra' que propone el establecimiento de procesos de concertación y negociación entre los distintos actores, armados y sociales, que hicieron parte del conflicto, ya sea de forma directa o indirecta.

En el caso de Colombia, este tema se torna complejo debido a la preponderancia de un modelo de negociación, poco o nada estructurado, con los distintos grupos insurgentes. En ocasiones, ha sido planteado como un modelo en el cual priman intereses individuales, cuyos fines atienden a la obtención de un beneficio determinado para ciertos sectores. Este esquema ha imperado sobre el modelo de negociación global que buscaba entablar diálogos, no solamente con el conjunto de la insurgencia guerrillera, sino también con los demás actores armados del conflicto, en este caso, los grupos de autodefensas y paramilitares ${ }^{33}$. 
En cambio, el posacuerdo surge como resultado del Acuerdo de Paz que se llevó a cabo entre el gobierno colombiano y las FARC, después de la firma del 26 de septiembre de 2016. Como consecuencia de ese actuar, hoy en día en Colombia se habla de posacuerdo por la trascendencia del tiempo del Acuerdo de Paz, situación que permite la institucionalidad de la Justicia Transicional.

En ambas etapas, los miembros de las fuerzas militares de Colombia han reiterado su vocación de servicio al país y han actuado conforme las disposiciones encomendadas para garantizar la defensa y la seguridad nacional. Por ello, se convierten en una institución de referencia superlativa al evaluarse las consecuencias del conflicto armado interno.

Por tanto, no es posible generar una condición secundaria o accesoria a las fuerzas militares colombianas en la etapa del posacuerdo, porque la institucionalidad militar seguirá siendo parte esencial de las acciones defensa y seguridad nacional del Estado, prioritarias para la supervivencia de la nación.

La variación de objetivos que deberán ser asumidos no impone la necesaria acción de anular los hechos sucedidos. Por ello, resulta necesario que los integrantes de las fuerzas militares colombianas también puedan ser reconocidos como víctimas del conflicto armado interno, si es que cumplen con las condiciones que detalla la Ley 1448 de 10 de junio de 2011.

Una acción contraria podría provocar algunas situaciones que la doctrina comparada ya ha registrado en la realidad peruana:

- Una disminución en el personal militar, lo que reduce su capacidad operativa e institucionalidad social.

- Una estigmatización social, producto de acciones y situaciones negativas que se dieron en el conflicto armado interno, provocadas por parte de los miembros de las fuerzas militares.

- Una condición negativa que afecta el sincretismo, la identificación y la asimilación de una organización institucional militar, por parte de aquellos que ya forman parte de las fuerzas militares, ante su situación personal en comparación con lo que han producido las FARC-EP respecto a sus integrantes.

- Finalmente, habrá una condición negativa en el ámbito social y familiar en la sociedad colombiana. Esta verá de poca utilidad el ser parte de la institución militar, porque permitirá proyectar que el compromiso personal con la patria no tenga el mismo valor al momento de evaluar una condición de víctima comparado con un hecho a raíz del cumplimiento de un deber.

\section{Conclusiones}

Con respecto al contexto del conflicto armado interno, el Acuerdo de Paz, el posacuerdo y la etapa del posconflicto, consideramos importante hacer una evaluación de la importancia del factor humano de las fuerzas militares de Colombia, principalmente por su rol activo en la etapa precedente y su condición de subordinación administrativa y militar ante sus comandos, institución y Estado.

Una valoración que requiere ser configurada de tal manera que pueda honrar el sacrificio de miles de soldados, marineros y pilotos colombianos, que arriesgaron su integridad física y psicológica, sus vidas, y el futuro de su familia. Este factor permitirá que el Estado no los condicione a una situación de invisibilidad ante el desarrollo e institucionalización de la Justicia Transicional.

La incidencia a un nivel de afectación a la Defensa y Seguridad Nacional puede ser negativa. Por ello planteamos valorar el factor humano de los miembros de las fuerzas militares de Colombia, y reconocer sus derechos como víctimas del conflicto armado interno. 


\section{Referencias}

ACNUR Comité Español, ¿Qué es un conflicto armado según el Derecho Internacional Humanitario? (mayo, 2018). h ttps://eacnur.org/blog/que-es-un-conflicto-armado-segun-el-derecho-internacional-humanitario/

Alfonso Valenzuela Aguilar, La eficacia colectiva como estrategia de control social del espacio barrial: evidencias desde Cuernavaca, México. 27 Revista Invi n.o 74, 187-215 (2012). https://scielo.conicyt.cl/pdf/invi/v27n74/art06. pdf

Araceli Mangas Martín, Conflictos armados internos y Derecho Internacional Humanitario (Universidad de Salamanca, 1992).

Carlos Basombrio \& Fernando Rospigliosi, La seguridad y sus instituciones en el Perú a inicios del siglo XXI: reformas democráticas o neomilitarismo (Instituto de Estudios Peruanos, 2006)

Carlos Contreras \& Marcos Cueto, Historia del Perú Contemporáneo: Desde las luchas por la independencia hasta el presente (Instituto de Estudios Peruanos, Universidad del Pacífico, 2007).

Corte Constitucional de Colombia. Sentencia C-161 de 2016 (M. P. Luís Ernesto Vargas Silva; 7 de abril de 2016).

Corte Constitucional de Colombia. Sentencia C-250 de 2012 (M. P. Humberto Antonio Sierra Porto; 28 de marzo de 2012).

Corte Constitucional de Colombia. Sentencia C-280 de 2013 (M. P. Nilson Pinilla Pinilla; 15 de mayo de 2013).

Corte Constitucional de Colombia. Sentencia T-092 de 2019 (M. P. Gloria Stella Ortiz Delgado; 4 de marzo de 2019).

Ejército del Perú, Manual Directriz, informe de gestión y autoevaluación institucional (2019).

Francisco Gutiérrez Sanín, Confiscar a los criminales para redistribuir a los campesinos: liberalismo e inclusio\#n social en el campo colombiano, en Tierra y paz: reformas de inclusio\#n social para una paz (2015). http://www.observator iodetierras.org/wp-content/uploads/2015/11/Francisco-Guti\%C3\%A9rrez.pdf

Germán Nicolás Pataquiva García, Las FARC, su origen y evolución, UNISCI Discussion Papers, n. ${ }^{\circ}$ 19, 154-184 (2009). https://www.redalyc.org/pdf/767/76711407010.pdf

Grupo de Memoria Histórica,;BASTA YA! Colombia: Memorias de guerra y dignidad, Informe General (Centro Nacional de Memoria Histo\#rica, 2014). https://www.centrodememoriahistorica.gov.co/descargas/informes2 013/bastaYa/basta-ya-colombia-memorias-de-guerra-y-dignidad-2016.pdf

Gustavo Marín, Richard Petris, Manfred Rosemberger, Patrice Mompayssin \& Carlos Novoa, Defensa y la carta de responsabilidades humanas, en Conversatorios preparatorios del Congreso Internacional: riesgos, seguridad y defensa en el siglo XXI. ASOCACI-FESCOL (2009). http://library.fes.de/pdf-files/bueros/kolumbien/0721 4.pdf

Jaime Cubides-Cárdenas, Paola Alexandra Sierra-Zamora \& María Dolores Núñez-Ávila, El Fuero Militar en el derecho colombiano vs. el derecho ecuatoriano, en El fuero militar: Justicia interamericana y Operaciones para el Mantenimiento de la Paz, 64-81 (Jaime Cubides Cárdenas, ed., 2017). https://doi.org/10.21830/9789585962 767

John Cornwell, Los científicos de Hitler: ciencia, guerra y pacto con el diablo (Paidós, 2005).

Julio López-Davalillo \& Eva Martín Roda, Geopolítica: claves para entender un mundo cambiante (Editorial Universitaria Ramón Areces, 2017).

Kim Vicente, The Human Factor: Revolutionizing the Way People Live with Technology (2004).

Ley 1448 de 2011. Por la cual se dictan medidas de atención, asistencia y reparación integral a las víctimas del conflicto armado interno y se dictan otras disposiciones. 10 de junio de 2011 D.O. 48096.

Malcom Deas, Intercambios violentos (Taurus, 2015).

Manuel Bermúdez Tapia, La atención e identificación de la víctima de violencia familia: ¿Limitaciones $y / 0$ negligencia jurisdiccional del Estado, Actualidad Civil, n. ${ }^{\circ} \quad 50, \quad 81-98$ (2018). https://www.academia.edu/44762238/La_atención_e_identificación_de_la_v\%C3\%ADctima_de_vi olencia_familiar_Limitaciones_y_o_negligencia_jurisdiccional_del_Estado 
Miguel Borja, La historiografia de la guerra en Colombia durante el siglo XIX, 28 Análisis político, n. 85, 173-188 (2015). https://doi.org/10.15446/anpol.v28n85.56253

Miller Soto Solano, La integración social de los discapacitados. Análisis de la normativa internacional en materia de discapacidad desde la perspectiva colombiana, 9 Justicia Juris, n. ${ }^{\circ}$ 2, 20-31. http://www.scielo.org.co/pdf/jusju/v $9 \mathrm{n} 2 / \mathrm{v} 9 \mathrm{n} 2 \mathrm{a} 03 . \mathrm{pdf}$

Paola Alexandra Sierra-Zamora \& Jaime Alfonso Cubides-Cárdenas, Derechos Humanos en Colombia: A raíz del conflicto armado con las FARC. Working Paper, n. 1 (2018).

Paola Alexandra Sierra-Zamora, La tutela de los Derechos Humanos en situaciones de postguerra: el caso colombiano. Working Paper, n. 2 (2018). https://doi.org/10.17605/OSF.IO/7KM83

Peter Calvocoressi, Historia política del mundo contemporáneo: de 1942 a nuestros días (Akal Ediciones, 1999).

Ricardo Melgar Bao, El Perú contemporáneo. El espejo de las identidades (UNAM, 1993).

Rodolfo Stavenhagen, Conflictos étnicos y estado nacional (Siglo XXI Editores, 2000).

Tito Hernando Pérez Pérez, Conflicto y posconflicto en Colombia: una mirada a la política de seguridad democrática, 5 Magistro, n. ${ }^{\circ}$ 10, 129-150 (2011). https://dialnet.unirioja.es/descarga/articulo/3948593.pdf

Vandana Shiva, Las guerras del agua: contaminación, privatización y negocio (Icaria, 2004).

Víctor Hugo Chanduví Cornejo \& Manuel Bermúdez Tapia, Temas de gestión pública (Universidad Privada Antenor Orrego, 2016).

\section{Notas}

* Artículo de investigación. Este artículo expone resultados de investigación del Proyecto Titulado: "Estrategia nacional. Por una Política de Seguridad y Defensa a la vanguardia de las amenazas contemporáneas" de la línea de investigación Educación Militar, liderazgo y doctrina perteneciente al Grupo de Investigación Masa Crítica reconocido y categorizado como C por Colciencias y registrado con el código COL0123247, vinculado a la Escuela Superior de Guerra.

1 Carlos Basombrio \& Fernando Rospigliosi, La seguridad y sus instituciones en el Perú a inicios del siglo XXI: reformas democráticas o neomilitarismo, 129 (Instituto de Estudios Peruanos, 2006)

2 Carlos Contreras \& Marcos Cueto, Historia del Perú Contemporáneo: Desde las luchas por la independencia hasta el presente, 374 (Instituto de Estudios Peruanos, Universidad del Pacífico, 2007).

3 Ejército del Perú, Manual Directriz, informe de gestión y autoevaluación institucional (2019).

4 Paola Alexandra Sierra-Zamora, La tutela de los Derechos Humanos en situaciones de postguerra: el caso colombiano. Working Paper, n. 2 (2018).

5 Ley 1448 de 2011. Por la cual se dictan medidas de atención, asistencia y reparación integral a las víctimas del conflicto armado interno y se dictan otras disposiciones. 10 de junio de 2011 D.O. 48096.

6 Corte Constitucional de Colombia. Sentencia C-250 de 2012 (M. P. Humberto Antonio Sierra Porto; 28 de marzo de 2012).

7 Corte Constitucional de Colombia. Sentencia C-280 de 2013 (M. P. Nilson Pinilla Pinilla; 15 de mayo de 2013).

8 Corte Constitucional de Colombia. Sentencia C-161 de 2016 (M. P. Luís Ernesto Vargas Silva; 7 de abril de 2016).

9 Corte Constitucional de Colombia. Sentencia T-092 de 2019 (M. P. Gloria Stella Ortiz Delgado; 4 de marzo de 2019).

10 Manuel Bermúdez Tapia, La atención e identificación de la víctima de violencia familia: ¿Limitaciones y/o negligencia jurisdiccional del Estado, Actualidad Civil, n.. 50, $81-98$ (2018).

11 Kim Vicente, The Human Factor: Revolutionizing the Way People Live with Technology (2004).

12 Ricardo Melgar Bao, El Perú contemporáneo. El espejo de las identidades, 126 (UNAM, 1993).

13 Sentencia C-251 de 2002 
14 Paola Alexandra Sierra-Zamora \& Jaime Alfonso Cubides-Cárdenas, Derechos Humanos en Colombia: A raíz del conflicto armado con las FARC. Working Paper, n. 1 (2018).

15 Víctor Hugo Chanduví Cornejo \& Manuel Bermúdez Tapia, Temas de gestión pública, 190 (Universidad Privada Antenor Orrego, 2016).

16 Gustavo Marín, Richard Petris, Manfred Rosemberger, Patrice Mompayssin \& Carlos Novoa, Defensa y la carta de responsabilidades humanas, en Conversatorios preparatorios del Congreso Internacional: riesgos, seguridad y defensa en el siglo XXI. ASOCACI-FESCOL, 7 (2009).

17 Peter Calvocoressi, Historia política del mundo contemporáneo: de 1942 a nuestros días (Akal Ediciones, 1999).

18 Julio López-Davalillo \& Eva Martín Roda, Geopolítica: claves para entender un mundo cambiante, 345 (Editorial Universitaria Ramón Areces, 2017).

19 John Cornwell, Los científicos de Hitler: ciencia, guerra y pacto con el diablo (Paidós, 2005).

20 Vandana Shiva, Las guerras del agua: contaminación, privatización y negocio, 345 (Icaria, 2004).

21 Gustavo Marín, Richard Petris, Manfred Rosemberger, Patrice Mompayssin \& Carlos Novoa, op. cit.

22 Rodolfo Stavenhagen, Conflictos étnicos y estado nacional (Siglo XXI Editores, 2000).

23 ACNUR Comité Español, ¿Qué es un conflicto armado según el Derecho Internacional Humanitario? (mayo, 2018).

24 Araceli Mangas Martín, Conflictos armados internos y Derecho Internacional Humanitario (Universidad de Salamanca, 1992).

25 Malcom Deas, Intercambios violentos, 7 (Taurus, 2015).

26 Francisco Gutiérrez Sanín, Confiscar a los criminales para redistribuir a los campesinos: liberalismo e inclusio\#n social en el campo colombiano, en Tierra y paz: reformas de inclusio\#n social para una paz (2015).

27 Miller Soto Solano, La integración social de los discapacitados. Análisis de la normativa internacional en materia de discapacidad desde la perspectiva colombiana, 9 Justicia Juris, n. ${ }^{\circ}$ 2, 20-31.

28 Alfonso Valenzuela Aguilera, La eficacia colectiva como estrategia de control social del espacio barrial: evidencias desde Cuernavaca, México, 27 Revista Invi n. ${ }^{\circ}$ 74, 193 (2012)

29 Jaime Cubides-Cárdenas, Paola Alexandra Sierra-Zamora \& María Dolores Núñez-Ávila, El Fuero Militar en el derecho colombiano vs. el derecho ecuatoriano, en El fuero militar: Justicia interamericana y Operaciones para el Mantenimiento de la Paz, 64-81 (Jaime Cubides Cárdenas, ed., 2017).

30 Grupo de Memoria Histórica, ¡BASTA YA! Colombia: Memorias de guerra y dignidad, Informe General (Centro Nacional de Memoria Histo\#rica, 2014).

31 Miguel Borja, La historiografía de la guerra en Colombia durante el siglo XIX, 28 Análisis político, n. ${ }^{\circ}$ 85, 173-188 (2015).

32 Germán Nicolás Pataquiva García, Las FARC, su origen y evolución, UNISCI Discussion Papers, n. ${ }^{\circ}$ 19, $154-184$ (2009).

33 Tito Hernando Pérez Pérez, Conflicto y posconflicto en Colombia: una mirada a la politica de seguridad democrática, 5 Magistro, n. ${ }^{\circ} 10,129-150(2011)$.

\section{Licencia Creative Commons CC BY 4.0}

Cómo citar este artículo: Paola Alexandra Sierra-Zamora \& Manuel Bermúdez Tapia, La invisibilidad de la identificación de victimas en las fuerzas militares y el inicio de una crisis en la defensa y seguridad nacional a raiz del Acuerdo de Paz, 69 Vniversitas (2020). https://doi.org/10.11144/Javeriana.vj69.iivf 